\title{
Online advertising and marketing claims by providers of proton beam therapy: are they guideline-based?
}

\author{
Mark T. Corkum', Wei Liu', David A. Palma', Glenn S. Bauman', Robert E. Dinniwell', Andrew Warner',
} Mark V. Mishra ${ }^{3}$ and Alexander V. Louie $e^{1,2^{*}}$

\begin{abstract}
Background: Cancer patients frequently search the Internet for treatment options, and hospital websites are seen as reliable sources of knowledge. Guidelines support the use of proton radiotherapy in specific disease sites or on clinical trials. This study aims to evaluate direct-to-consumer advertising content and claims made by proton therapy centre (PTC) websites worldwide.

Methods: Operational PTC websites in English were identified through the Particle Therapy Co-Operative Group website. Data abstraction of website content was performed independently by two investigators. Eight international guidelines were consulted to determine guideline-based indications for proton radiotherapy. Univariate and multivariate logistic regression models were used to determine the characteristics of PTC websites that indicated proton radiotherapy offered greater disease control or cure rates.

Results: Forty-eight PTCs with 46 English websites were identified. 60.9\% of PTC websites claimed proton therapy provided improved disease control or cure. U.S. websites listed more indications than international websites $(15.5 \pm 5.4$ vs. $10.4 \pm 5.8, p=0.004)$. The most common disease sites advertised were prostate (87.0\%), head and neck (87.0\%) and pediatrics (82.6\%), all of which were indicated in least one international guideline. Several disease sites advertised were not present in any consensus guidelines, including pancreatobiliary (52.2\%), breast (50.0\%), and esophageal (43.5\%) cancers. Multivariate analysis found increasing number of disease sites and claiming their centre was a local or regional leader in proton radiotherapy was associated with indicating proton radiotherapy offers greater disease control or cure.

Conclusions: Information from PTC websites often differs from recommendations found in international consensus guidelines. As online marketing information may have significant influence on patient decisionmaking, alignment of such information with accepted guidelines and consensus opinion should be adopted by PTC providers.
\end{abstract}

\section{Background}

The internet is a widely accessed source of medical information for patients [1-8]. Direct-to-consumer advertising (DTCA) on hospital and healthcare organization websites is common [9], however frequently do not adequately support their claims with reference to available evidence [10].

\footnotetext{
* Correspondence: Alexander.Louie@|hsc.on.ca

'Department of Radiation Oncology, London Health Sciences Centre, 790

Commissioners Road East, London, ON N6A 4L6, Canada

${ }^{2}$ Department of Epidemiology and Biostatistics, Western University, London, Canada

Full list of author information is available at the end of the article
}

While print and broadcast media must conform to nationally regulated standards, there is currently no regulation of DTCA by healthcare websites despite potential conflict of interests $[3,10,11]$.

Controversial DTCA for new oncology treatments has been previously identified $[9,12]$. Patients with cancer may be especially vulnerable to controversial marketing due to associated fear and anxiety [11, 13]. As cancer patients may place more confidence in online information when endorsed by professional bodies and organizations $[3,9]$, it has been argued that strict guidelines and more 
oversight should be implemented for marketing by cancer centres to patients with cancer [9-11, 13].

Proton beam therapy (PBT) is a rapidly emerging technology with desirable dosimetric advantages compared to traditional photon radiotherapy (RT). PBT takes advantage of the "Bragg peak", allowing for deposition of radiation to a tumour target with minimal to no exit dose affecting normal tissues beyond. Routine adoption of proton beam therapy faces several challenges. High capital and operating costs create barriers to institutional and individual patient access to PBT [14], particularly as insurers may be reluctant to cover treatments where there is an insufficient evidence base to justify higher cost PBT compared to lower cost alternatives $[15,16]$. Despite these barriers, utilization of PBT is increasing [17], mirroring the rapid rise in number of PBT centres worldwide. Controversial online advertising practices with PBT have previously been identified, targeted towards men with prostate cancer [18]. International published guidelines only recommend PBT for a limited number of disease sites [19-27].

While heavy ion radiotherapy dates as far back as the 1930 's, it was only after Loma Linda opened a threegantry facility in 1990 that the number of PBT centres began to rise rapidly [28]. As of September 2016, there were 62 operating PBT internationally, including 25 in the United States, 11 in Japan, and 6 in Germany [29]. There are 37 additional PBT centres under construction around the world [30]. Business models for PBT differ across these jurisdictions and ultimately, regardless of payer, such facilities become economically viable only when there are sufficient patient volumes to fully utilize such facilities. The purpose of our study was to compare DTCA content and claims on proton therapy centre (PTC) websites against current evidence based indications (as reflected in published guidelines) to characterize the frequency and nature by which PBT is being promoted for non-evidence based indications.

\section{Methods}

\section{Study population}

All operating PTCs worldwide as of September 1, 2016 were identified on the Particle Therapy Co-operative Group website (https://www.ptcog.ch/). The website of each centre was reviewed to confirm its operational status. We excluded PTCs without an English website and three centres that solely treat ocular tumours, as they lack sufficient energy to treat deeper tumours. The websites of facilities under construction and facilities in planning stage identified by the Particle Therapy Co-operative Group were then reviewed and one additional operational centre was identified. A separate Internet search did not reveal any additional centres. We also searched the websites of the five PBT manufacturers with centres in the United States to confirm that our list of PTCs was complete. Our final study population consisted of forty-eight operational PTCs and forty-six PTC websites.

\section{Data collection}

The websites of PTCs were evaluated using a standardized data collection form, adapted from previously published studies assessing hospital website DTCA [9, 12]. The data collection form is available in Additional file 1: Appendix A. In two instances, two PTC's were represented by a single website; data was collected once for these PTCs. Data was collected independently by two investigators (MC and WL), with discrepancies reached by consensus after further review of the websites and discussion with a third investigator (AVL).

We evaluated for advertising prominence and compliance with the American Medical Association Opinion on Advertising and Publicity [31,32]. Data collected from each centre's website included: disease sites that were claimed to be treatable with PBT, whether PBT was available as a clinical trial and details regarding accessibility (cost, travel). Data regarding claims of efficacy, decreased morbidity, and/or comparisons between PBT and RT were also collected. Website traffic was evaluated using Alexa Rank (http://www.alexa.com) [33]. Population estimates for the region served by the PBT centre were obtained from Population Explorer (https:// populationexplorer.com), an international tool developed by Kimetrica for the U.S. Agency for International Development's Famine Early Warning System Network. Academic practices were defined as those associated with a medical school and/or residency training program; where doubt existed, supplemental internet searches were performed to clarify.

Eight international guidelines were consulted to determine disease sites potentially suitable for treatment with proton radiotherapy [19-27]. According to these guidelines, disease sites that were definitely or potentially indicated for PBT by two or more guidelines included: pediatric, eye/orbit, benign central nervous system (CNS), low-grade glioma, other CNS (e.g. spine/bone, base of skull), liver, head and neck, lymphoma, sarcomas and recurrent disease. Four disease sites (palliative treatments, prostate, lung and bone cancers) were only mentioned by a single guideline, and were included in our study as indicated sites. If a website listed more generic terms (e.g. glioma instead of low-grade glioma, base of skull or spine tumour instead of chordoma/ chondrosarcoma, etc.), it was included as a potentially indicated PBT despite the possibility this could include non-indicated diagnoses. All other disease sites collected were considered not to be endorsed by the consensus international guidelines for PBT treatment. 


\section{Statistical analysis}

Descriptive statistics were generated for all websites and compared between those advertised in the U.S. versus internationally using the chi-square test, Fisher's exact test, two-sample T-test or Wilcoxon rank sum test as appropriate. Where more than one PTC was represented by a single website, attempts were made to collect separate demographic data and report it separately. For variables analyzed at a website level, data were not counted multiple times. This study was written to meet requirements published within the STROBE statement [34].

Univariate and multivariate logistic regression was performed to identify characteristics of websites that were predictive of greater disease control or cure rates. Explanatory variables included in the univariate logistic regression analyses were determined a priori. Multivariate logistic regression initially included univariate variables with a $p$-value $<0.10$ for each end point. These variables were sequentially removed using backward elimination until all remaining covariates had $p$-values $<0.05$. To allow multivariate analysis for websites representing two centres, we chose to include demographic data from the PTC with the greatest surrounding population. All statistical analysis was performed using SAS version 9.4 software (SAS institute, Cary NC), using two-sided statistical testing at the 0.05 significance level.

\section{Results}

Forty-eight PTC centres were identified resulting in forty-six PTC websites for analysis. Additional file 2: Appendix B summarizes included and excluded PTC's including reason for exclusion. Features of included websites are presented in Table 1. Twenty-four PTCs (with twenty-two websites) were from the United States, $62.5 \%$ were considered academic centres and $47.8 \%$ of webpages listed the manufacturer of their proton treatment machine, of which $45.5 \%$ claimed that their machine was superior. PBT-specific patient testimonials were present on $43.5 \%$ of websites, and $63.0 \%$ included a section dedicated to out-of-town patients. The amount of information contained within each website varied greatly, from single webpages only containing general information to detailed discussions about the merits of PBT for specific disease sites.

Selected treatable disease sites listed on PTC websites are presented in Table 2. A full list of disease sites mentioned on websites is available in Additional file 3: Appendix C. The mean number of disease sites listed on all websites was $12.8 \pm 6.1$, with $15.5 \pm 5.4$ for U.S. compared to $10.4 \pm 5.8$ for international $(p=0.004)$. The most common disease sites listed on websites were prostate (87.0\%), head and neck (87.0\%), and pediatric tumours (82.6\%). Several disease sites advertised were not present in any international consensus guidelines, including
Table 1 Information about Proton Therapy Centre Websites

\begin{tabular}{|c|c|}
\hline & $\begin{array}{l}\text { All Websites \% }(n) \\
(N=46 \text { unless } \\
\text { otherwise specified) }\end{array}$ \\
\hline \multicolumn{2}{|l|}{ Proton Centre Location $(N=48)$} \\
\hline United States & $50.0 \%(24)$ \\
\hline Asia & $31.3 \%(15)$ \\
\hline Europe & $16.7 \%(8)$ \\
\hline Africa & $2.1 \%(1)$ \\
\hline Website from an Academic Proton Centre $(N=48)$ & $62.5 \%(30)$ \\
\hline Another Proton Centre within 300 km (N=48) & $52.1 \%(25)$ \\
\hline \multicolumn{2}{|c|}{ Population Estimate within $100 \mathrm{~km}$ of Proton Centre $(N=48)$} \\
\hline$\leq 2,499,999$ & $18.8 \%(9)$ \\
\hline $2,500,000-4,999,999$ & $25 \%(12)$ \\
\hline $5,000,000-9,999,999$ & $20.8 \%(10)$ \\
\hline$\geq 10,000,000$ & $35.4 \%(17)$ \\
\hline \multicolumn{2}{|l|}{ Number of Clicks to First Page Mentioning Proton Therapy } \\
\hline 0 (directly on homepage) & $56.5 \%(26)$ \\
\hline 1 & $26.1 \%(12)$ \\
\hline$\geq 2$ & $17.4 \%(8)$ \\
\hline Manufacturer of Machine Listed & $47.8 \%(22)$ \\
\hline Claim Their Proton Machine Superior $(N=22)$ & $45.5 \%(10)$ \\
\hline $\begin{array}{l}\text { Stock Material from Manufacturer Present } \\
(N=22)\end{array}$ & $31.8 \%(7)$ \\
\hline $\begin{array}{l}\text { Stock Material Acknowledged from } \\
\text { Manufacturer }(N=7)\end{array}$ & $42.9 \%(3)$ \\
\hline Link to Manufacturer Website Present $(N=22)$ & $13.6 \%(3)$ \\
\hline \multicolumn{2}{|l|}{ Number of Clicks to Mention of Manufacturer $(N=22)$} \\
\hline 0 (directly on homepage) & $13.6 \%(3)$ \\
\hline 1 & $40.9 \%(9)$ \\
\hline$\geq 2$ & $45.5 \%(10)$ \\
\hline Out-of-Town Patient Section on Website & $63.0 \%(29)$ \\
\hline Proton Therapy Patient Testimonials on Website & $43.5 \%(20)$ \\
\hline
\end{tabular}

pancreatobiliary (52.2\%), breast (50.0\%), esophageal (43.5\%), colorectal (39.1\%) and gynecologic (30.4\%) cancers.

Several disease sites were more frequently mentioned on U.S. websites in comparison to international websites, including spinal $(77.3 \%$ vs. $41.7 \%$; $p=0.014)$, anal $(36.4 \%$ vs. $0 \% ; p=0.001)$, colorectal ( $54.6 \%$ vs. $25.0 \%, p=0.040)$, stomach $(31.8 \%$ vs. $4.2 \% ; p=0.020)$, breast $(77.3 \%$ vs. $25.0 \% ; p$ $<0.001)$, lymphoma (68.2\% vs. $16.7 \% ; p<0.001)$, lung $(95.5 \%$ vs. $58.3 \% ; p=0.003)$ and pediatric tumours $(95.5 \%$ vs. $70.8 \%, p=0.049$ ).

Claims made by PTC websites are presented in Table 3. Sixty-one percent of websites claimed proton therapy provided improved disease control or cure, with $13.0 \%$ of websites stating that for at least one disease site PBT was the standard of care treatment. Sixty-one percent of websites stated that proton therapy was more effective 
Table 2 Proportion of Selected Disease Sites Mentioned on Proton Therapy Centre Websites

\begin{tabular}{|c|c|c|c|c|}
\hline Site & All Websites \% $(n)(N=46)$ & $\begin{array}{l}\text { US Websites \% (n) } \\
(N=22)\end{array}$ & $\begin{array}{l}\text { International Websites \% ( } \mathrm{n}) \\
(N=24)\end{array}$ & $\begin{array}{l}\text { US v. Int'I } \\
p \text {-value }\end{array}$ \\
\hline \multicolumn{5}{|l|}{ Number of Sites Listed } \\
\hline$($ mean $\pm S D)$ & $12.8 \pm 6.1$ & $15.5 \pm 5.4$ & $10.4 \pm 5.8$ & $\underline{0.004}$ \\
\hline Adult CNS (any) ${ }^{*}$ & $89.1 \%(41)$ & $95.5 \%(21)$ & $83.3 \%(20)$ & 0.349 \\
\hline Benign & $58.7 \%(27)$ & $63.6 \%(14)$ & $54.2 \%(13)$ & 0.515 \\
\hline Glioma (High or Low Grade) & $45.7 \%(21)$ & $50.0 \%(11)$ & $41.7 \%(10)$ & 0.571 \\
\hline Other (e.g. base of skull) & $65.2 \%(30)$ & $59.1 \%(13)$ & $70.8 \%(17)$ & 0.404 \\
\hline Spine & $58.7 \%(26)$ & $77.3 \%(17)$ & $41.7 \%(10)$ & $\underline{0.014}$ \\
\hline Bladder & $19.6 \%(9)$ & $27.3 \%(6)$ & $12.5 \%(3)$ & 0.276 \\
\hline Breast & $50.0 \%(23)$ & $77.3 \%(17)$ & $25.0 \%(6)$ & $\leq 0.001$ \\
\hline Eye/Orbit & $58.7 \%(27)$ & $68.2 \%(15)$ & $50.0 \%(12)$ & 0.211 \\
\hline $\mathrm{Gl}$ (any) ${ }^{*}$ & $76.1 \%(35)$ & $90.9 \%(20)$ & $62.5 \%(15)$ & 0.024 \\
\hline Anal & $17.4 \%(8)$ & $36.4 \%(8)$ & $0 \%(0)$ & $\underline{0.001}$ \\
\hline Colorectal & $39.1 \%(18)$ & $54.6 \%(12)$ & $25.0 \%(6)$ & $\underline{0.040}$ \\
\hline Esophagus & $43.5 \%(20)$ & $54.6 \%(12)$ & $33.3 \%(8)$ & 0.147 \\
\hline Liver & $56.5 \%(26)$ & $54.6 \%(12)$ & $58.3 \%(14)$ & 0.796 \\
\hline Pancreatobiliary & $52.2 \%(24)$ & $68.2 \%(15)$ & $37.5 \%(9)$ & $\underline{0.037}$ \\
\hline Stomach & $17.4 \%(8)$ & $31.8 \%(7)$ & $4.2 \%(1)$ & $\underline{0.020}$ \\
\hline Gynecologic & $30.4 \%(14)$ & $36.4 \%(8)$ & $25.0 \%(6)$ & 0.403 \\
\hline Head and Neck & $87.0 \%(40)$ & $90.9 \%(20)$ & $83.3 \%(20)$ & 0.667 \\
\hline Kidney & $13.0 \%(6)$ & $4.6 \%(1)$ & $20.8 \%(5)$ & 0.190 \\
\hline Lymphoma & $41.3 \%(19)$ & $68.2 \%(15)$ & $16.7 \%(4)$ & $\leq 0.001$ \\
\hline Lung & $76.1 \%(35)$ & $95.5 \%(21)$ & $58.3 \%(14)$ & $\underline{0.003}$ \\
\hline Pediatric Tumours & $82.6 \%(38)$ & $95.5 \%(21)$ & $70.8 \%(17)$ & $\underline{0.049}$ \\
\hline Prostate & $87.0 \%(40)$ & $95.5 \%(21)$ & $79.2 \%(19)$ & 0.190 \\
\hline Recurrent Disease & $54.4 \%(25)$ & $54.6 \%(12)$ & $54.2 \%(13)$ & 0.979 \\
\hline Sarcoma & $67.4 \%(31)$ & $81.8 \%(18)$ & $54.2 \%(13)$ & $\underline{0.046}$ \\
\hline
\end{tabular}

*These sites contain additional categories not presented, available in Appendix C

All entries with $p<0.05$ are bolded with italic underline

(i.e. improved survival or local control) than photon RT. Ninety-eight percent of websites stated there was a dose distribution advantage to proton therapy: $84.8 \%$ stated fewer side effects, $39.1 \%$ stated improved quality-of-life and $84.8 \%$ and $21.7 \%$ of websites stated decreased morbidity compared to photon RT and surgery respectively. Discussion about the cost/insurance coverage of proton therapy and availability in clinical trial setting was present in $69.6 \%$ and $56.5 \%$ respectively.

References were infrequently provided on websites: $4.4 \%$ provided references for all claims with $32.6 \%$ further websites providing a scientific reference for at least one claim. Seven percent stated that their claims were backed by scientific studies without a reference whereas $56.5 \%$ did not provide any references.

On univariate analysis, increasing number of disease sites listed (odds ratio (OR) per additional site: 1.14, 95\% confidence interval (CI): 1.02-1.29, $p=0.025)$ and claiming to be a local/regional leader in PBT (OR: 4.67, 95\% CI: $1.22-17.82, p=0.024)$ were predictive of claiming better disease control or cure. Both of these factors remained significant on multivariate analysis (OR: 1.15, 95\% CI: $1.02-1.31, p=0.027$ and OR: $5.15,95 \%$ CI: $1.22-21.80, p=0.026$ respectively).

\section{Discussion}

Proton radiotherapy is a rapidly expanding treatment modality that has attractive dosimetric advantages compared to photon radiotherapy, albeit at an increased capital and per-fraction reimbursement costs [14]. The main findings of this study are that worldwide, PTC websites commonly contain DTCA for PBT that are frequently not supported by evidence, and often advertise the treatment of cancer sites not currently endorsed by international consensus guidelines. This did not appear to be localized to a single centre, country or disease site; 
Table 3 Claims Made on Proton Therapy Centre Websites

\begin{tabular}{ll}
\hline & $\begin{array}{l}\text { All Websites \% (n) } \\
\text { (N=46 unless } \\
\text { otherwise specified) }\end{array}$ \\
\hline Claims about Proton Therapy & \\
Improved Disease Control or Cure & $60.9 \%(28)$ \\
Standard of Care & $13.0 \%(6)$ \\
Fewer Side Effects & $84.8 \%(39)$ \\
Specific Side Effects Listed & $67.4 \%(31)$ \\
Quicker Recovery Time & $15.2 \%(7)$ \\
Increased Quality-of-Life & $39.1 \%(18)$ \\
Dose Distribution Advantage & $97.8 \%(45)$ \\
Claims and comparison to Other Modalities & \\
Photon RT: Increased Efficacy & $60.9 \%(28)$ \\
Photon RT: Decreased Morbidity & $84.8 \%(39)$ \\
Surgery: Increased Efficacy & $2.2 \%(1)$ \\
Surgery: Decreased Morbidity & $21.7 \%(10)$ \\
Evidence Provided for Claims on Website & \\
All Claims Referenced & $4.4 \%(2)$ \\
Some Claims Referenced & $32.6 \%(15)$ \\
Generic References (e.g. Studies show that...) & $6.5 \%(3)$ \\
No Claims Referenced & $56.5 \%(26)$ \\
Alternative Treatment(s) to Proton Therapy Listed & $89.1 \%(41)$ \\
Claim Local/Regional Leader in Proton Therapy & $43.5 \%(20)$ \\
Length of Time Treating/Patient Volume Listed & $71.7 \%(33)$ \\
Mention of Cost/Insurance of Proton Therapy & $69.6 \%(32)$ \\
\hline & $56.5 \%(26)$ \\
\hline
\end{tabular}

rather, this trend exists globally and for a multitude of cancer sites.

The ethical implications of DTCA within healthcare are neither new, nor unique to radiation oncology. Currently, the United States and New Zealand are the only two countries that permit print and broadcast DTCA within healthcare [35]; no countries regulate DTCA from online sources [11]. In the U.S., the Food and Drug Administration (FDA) regulates print and broadcast advertising: although only major risk information must be disclosed, they must direct consumers to other accessible sources of information on literature and all other associated risks [36]. Supporters of DTCA argue that it increases awareness, education and empowerment to facilitate patient-centred decision-making and decrease paternalistic care [37]. In contrast, arguments against DTCA include the high literacy level required, bypassing the patient-provider relationship, overutilization, and increased healthcare costs [37].

Cancer centres producing DTCA for new radiotherapy technologies was previously questioned with the introduction of Intensity Modulated Radiation Therapy
(IMRT) to mainstream radiation oncology practices in the 2000's [38]. While IMRT implementation was also questioned due to concerns of tumour targeting and risk of secondary malignancies (with larger volumes of normal tissues receiving low dose radiotherapy), the increased costs of IMRT were also a valid concern [39]. While the safety and accuracy of PBT have not been questioned to the same degree, the increased costs of PBT surpass those of IMRT, arising from both high capital costs plus increased reimbursement per fraction [14]. Traditional multi-room proton facilities cost in excess of 100 million USD [40], though single-room proton machines have now entered the market with a lower capital cost [41, 42]. Recent systematic reviews of the cost-effectiveness of PBT suggest superiority in several disease sites, such as particular pediatric brain tumours, left sided breast cancers at high risk of cardiac toxicity, selected head and neck cancers, and locally advanced lung cancers, acknowledging this finding is limited by the lack of published literature [43, 44].

As cancer care is highly profitable [45], it should not be surprising that spending on advertising is increasing. In 2014, \$173 million was spent on cancer centre advertising in the U.S., roughly triple the amount compared to 2005 [46]. Of the 1500 cancer centres in the U.S., 20 accounted for $86 \%$ of advertising spending, of which 9 were NCI-designated [46]. Of these 20 centres, five were included in our study. The advertising practices of cancer centres have previously been brought into question, including appeals to the emotions of a vulnerable patient population, hope for survival, and improved outcomes without supporting factual information, while not mentioning costs or risks associated with treatment [11, 13, 46-48]. Our study supports these findings, demonstrating PTC websites frequently offer PBT to non-guideline recommended cancer sites, contain language which evokes hope for better treatment outcomes, and infrequently support all claims made on their website.

It has been argued that randomized clinical trials for PBT are not necessary due to the clear dose distribution advantages over RT [44, 49]. In addition, it has been argued that the capacity constraints of PBT centres precludes the ability to perform randomized clinical trials [50]. While some side effects are likely to be improved with PBT, it is possible that certain side effects, such as skin toxicity, could be expected to be worse with intensity modulated proton therapy [51]. There are over 100 clinical trials underway examining proton radiotherapy, albeit with only eight randomized clinical trials directly comparing proton versus photon radiotherapy [52]. Recently, the first presentation of a randomized study between proton and photon radiotherapy of 147 patients with locally advanced non-small cell lung cancer was published in abstract form, finding no difference in 
treatment failure or $\geq$ grade 3 radiation pneumonitis between the two treatment modalities [53].

In the absence of randomized data, we examined 8 guidelines on proton therapy to identify disease sites indicated for PBT [19-27]. These guidelines are from the U.S., Canada, Australia and New Zealand, the U.K., Denmark and the Netherlands. The publication dates range from 2009 to 2017. Guidelines differ on disease site indications, therefore when determining disease sites indicated by guidelines, we used a threshold of at least one guideline indicating a disease site. After review of the international guidelines, there were four disease sites only endorsed by a single guideline (NCCN guidelines). These four sites (prostate cancer, lung cancer, bone cancers and palliative tumours), were considered to be indicated sites for purposes of our study. Prostate cancer was considered an indicated site despite the NCCN guideline also clearly stating that "They believe no clear evidence supports a benefit or decrement to proton therapy over IMRT for either treatment efficacy or long-term toxicity" [54]. Despite retrospective and prospective cohort studies demonstrating favourable side effect profiles for PBT in several disease sites not mentioned in these guidelines (such as pancreas [55], breast [56], esophagus [57] and cervical [58] cancers), these were not considered indications in our study as they have not been cited in guidelines to date, and are subject to bias.

To our knowledge, this is the first systematic evaluation of DTCA on English PTC websites. However, our data is limited by inconsistencies between how disease sites were listed in international guidelines and websites. For example, many websites did not separate high and low grade gliomas. Several guidelines support the use of PBT for low grade gliomas [19, 21, 24], but no guidelines support the use of PBT in high grade gliomas. Other limitations of our study are excluding ten websites that were not in English. Several international websites that did have an English webpage contained limited information relative to equivalent U.S. websites. As such, our data for these websites may not be completely representative of DTCA towards the primary target audience. Inclusion of a disease site within a guideline is one measure of alignment with evidence based care but has limitations. Guidelines may be limited by the evidence base available or may be influenced by expert opinion depending on the methodology used to generate the guideline. We did not incorporate the availability of pencil beam scanning in our study. Some PTC's offer both PBT and carbon ion therapy. At times, it was difficult to separate claims for PBT and carbon ion therapy. Finally, the nature of DTCA by an institution does not necessarily reflect the level of discussion that occurs at the provider/patient level. For example, while an indication might be listed on a DTCA website, an informed discussion with the patient may include discussions of alternatives and tailoring of recommendations to that individual's situation. Such provisos that acknowledge treatments need to be individualized ("check with your doctor if drug $\mathrm{x}$ is right for you") are a mainstay of other forms of DTCA but were not a prominent feature of the websites we examined.

\section{Conclusions}

Our study shows that PTC websites contain DTCA for disease sites that are not endorsed by international consensus guidelines, in addition to appealing to the emotions of patients by often claiming superior disease control or decreased side effect profiles. This follows the pattern of other cancer treatments such as robotic surgery for prostate cancer and stereotactic body radiation therapy. Similar to the early adoption of IMRT radiotherapy, we postulate that there is a need to balance rapid adoption of PBT as an emerging technology and establishing randomized evidence upon which the recommendation for PBT can be made. The results of this study highlight the urgent need for comparative effectiveness PBT research in order to develop updated and high-quality evidence-based recommendations that can be used to inform its judicious use and to generate appropriate informational materials for patients.

\section{Additional files}

Additional file 1: Appendix A: Data collection form. (DOCX $17 \mathrm{~kb}$ )

Additional file 2: Appendix B: Included and Excluded Proton Therapy Centers, sorted by country, state and city. (DOCX 19 kb)

Additional file 3: Appendix C: Proportion of All Disease Sites Mentioned on Proton Therapy Centre Websites. (DOCX $21 \mathrm{~kb}$ )

\section{Abbreviations}

Cl: Confidence Interval; CNS: Central Nervous System; DTCA: Direct-toConsumer Advertising; FDA: Food and Drug Administration; IMRT: Intensity Modulated Radiation Therapy; OR: Odds Ratio; PBT: Proton Beam Therapy; PTC: Proton Therapy Centre; RT: Radiotherapy

\section{Acknowledgements}

Not applicable.

Funding

Not applicable - no relevant funding sources.

\section{Availability of data and materials}

The datasets used and/or analysed during the current study are available from the corresponding author on request.

\section{Authors' contributions}

MC: Conceptualization, investigation, methodology, data curation, analysis and interpretation, writing (original draft and review/editing), visualization, and project administration. WL: Conceptualization, investigation, methodology, data curation, analysis and interpretation, writing (original draft and review/editing), and project administration. DP: Analysis and interpretation, and writing (review/editing). GB: Analysis and interpretation, and writing (review/editing). RD: Analysis and interpretation, and writing (review/editing). AW: Analysis and interpretation, writing (review/editing), and visualization. MM: Analysis and interpretation, and writing (review/ editing). AL: Conceptualization, investigation, methodology, data curation, 
analysis and intrepretation, writing (original draft and review/editing), supervision, and project administration. All authors read and approved the final manuscript.

\section{Ethics approval and consent to participate}

Not applicable.

\section{Consent for publication}

Not applicable.

\section{Competing interests}

AL has received speaker's honoraria from Varian Medical Systems Inc. His research is supported by the Schulich Clinician Scientist Award. DP is supported by the Ontario Institute for Cancer Research. GB has served as an advisor to the Ministry of Health and Long Term Care, Ontario, Canada as part of a provincial proton beam task force. The remainder of the authors have no conflicts of interest to disclose.

\section{Publisher's Note}

Springer Nature remains neutral with regard to jurisdictional claims in published maps and institutional affiliations.

\section{Author details}

${ }^{1}$ Department of Radiation Oncology, London Health Sciences Centre, 790 Commissioners Road East, London, ON N6A 4L6, Canada. ${ }^{2}$ Department of Epidemiology and Biostatistics, Western University, London, Canada. ${ }^{3}$ Departments of Radiation Oncology, University of Maryland School of Medicine, Baltimore, USA.

\section{Received: 13 January 2018 Accepted: 1 March 2018}

\section{Published online: 15 March 2018}

\section{References}

1. Macready N. Cancer patients connect on the internet. J Natl Cancer Inst. 2012;104:267-8. https://doi.org/10.1093/jnci/djs130.

2. Sidana A, Hernandez DJ, Feng Z, et al. Treatment decision-making for localized prostate cancer: what younger men choose and why. Prostate. 2012;72:58-64. https://doi.org/10.1002/pros.21406.

3. Maddock C, Lewis I, Ahmad K, Sullivan R. Online information needs of cancer patients and their organizations. Ecancermedicalscience. 2011;5:235. https://doi.org/10.3332/ecancer.2011.235.

4. Wald HS, Dube CE, Anthony DC. Untangling the web-the impact of internet use on health care and the physician-patient relationship. Patient Educ Couns. 2007;68:218-24. https://doi.org/10.1016/j.pec.2007.05.016.

5. Johnson PT, Chen JK, Eng J, Makary MA, Fishman EK. A comparison of world wide web resources for identifying medical information. Acad Radiol. 2008; 15:1165-72. https://doi.org/10.1016/j.acra.2008.02.010.

6. Hartzband P, Groopman J. Untangling the web - patients, doctors and the internet. N Engl J Med. 2010;362:1063-6. https://doi.org/10.1056/ NEJMp0911938.

7. Ziebland S, Chapple A, Dumelow C, et al. How the internet affects patients' experience of cancer: a qualitative study. BMJ. 2004;328:564 https://doi.org/10.1136/bmj.328.7439.564.

8. Chen X, Siu LL. Impact of the media and the internet on oncology: survey of cancer patients and oncologists in Canada. J Clin Oncol. 2001;19:4291-7.

9. Jin LX, Ibrahim AM, Newman NA, et al. Robotic surgery claims on United States hospital websites. J Healthc Qual. 2011:33:48-52. https://doi.org/10.1111/j.1945-1474.2011.00148.x.

10. Pronovost PJ, Miller M, Wachter RM. The GAAP in quality measurement and reporting. JAMA. 2007;298:1800-2. https://doi.org/10.1001/jama.298.15.1800.

11. Holcombe RF. The ethics of marketing cancer. J Cancer Policy. 2015;3:1-2. https://doi.org/10.1016/j.jcpo.2014.11.001.

12. Narang AK, Lam E, Makary MA, et al. Accuracy of marketing claims by providers of stereotactic radiation therapy. J Oncol Pract. 2013:9:57-62. https://doi.org/10.1200/JOP.2012.000693

13. Palmer $\mathrm{D}$, Hedberg $\mathrm{T}$. The ethics of marketing to vulnerable populations. J Bus Ethics. 2013;116:403-13. https://doi.org/10.1007/s10551-012-1476-2.

14. Varian Medical Systems. Summary of 2016 final Medicare payment rules 2015. https://www.varian.com/sites/default/files/resource_attachments/
2016_Final_Medicare_Payment_Rules_Rad\%23_10405.docx_pdf (Accessed 9 Jan 2017).

15. Shah A, Ricci Kl, Efstathiou JA. Beyond a moonshot: insurance coverage for proton therapy. Lancet Oncol. 2016;17:559-61. https://doi.org/10.1016/S1470-2045(16)00171-6.

16. Halperin EC. The proton problem. Lancet Oncol. 2013;14:1046-8. https://doi.org/10.1016/S1470-2045(13)70443-1.

17. Jarosek S, Elliott S, Virnig BA. Proton beam radiotherapy in the U.S. Medicare population: growth in use between 2006 and 2009: data points \# 10. Rockville: US Agency for Healthcare Research and Quality; n.d. 2012.

18. Basto M, Cooperberg MR, Murphy DG. Proton therapy websites: information anarchy creates confusion. BJU Int. 2015;115:183-5.

19. Patel $S$, Kostaras $X$, Parliament $M$, et al. Recommendations for the referral of patients for proton-beam therapy, an Alberta Health Services report: a model for Canada? Curr Oncol. 2014:21:251-62. https://doi.org/10.3747/co.21.2207.

20. American Society for Radiation Oncology. Model policies: proton beam therapy 2014. https://www.astro.org/uploadedFiles/Main Site/Practice Management/Reimbursement/ASTRO PBT Model Policy FINAL.pdf (Accessed 4 Jan 2017).

21. National Health Services England. Guidance for the referral of patients abroad for NHS proton treatment 2011. https://www.england.nhs.uk/wpcontent/uploads/2014/09/guidance-referral-pat-abroad-nhs-proton.pdf (Accessed 4 Jan 2017).

22. Department of Health (United Kingdom). National PBT service development Programme - value for money addendum to the strategic outline case 2012. https://www.gov.uk/government/uploads/system/uploads/ attachment_data/file/213045/national-proton-beam-therapy-servicedevelopment-programme-value-for-money-addendum.pdf (Accessed 4 Jan 2017).

23. Institute for Clinical and Economic Review. Proton beam therapy final evidence report 2014. https://icer-review.org/wp-content/uploads/2014/07/ pbt final report_040114.pdf (Accessed 4 Jan 2017).

24. The Royal Australian and New Zealand College of Radiologists. Position paper on particle therapy 2015. http://www.ranzcr.edu.au/documentsdownload/document-library-2/document-library-4/3971-20151118-positionpaper-on-particle-therapy-final (Accessed 4 Jan 2017).

25. Aarhus University. The Danish National Center for particle radiotherapy 2012. https://www.rm.dk/siteassets/om-os/a_udbud/dnu_partikelterapi/detnationale-center-for-partikelterapi-2012.pdf (Accessed 4 Jan 2017).

26. Health Council of the Netherlands. Proton radiotherapy 2009. https://www. gezondheidsraad.nl/sites/default/files/proton_radiotherapy200917E_0.pdf (Accessed 4 Jan 2017)

27. National Comprehensive Cancer Network. NCCN guidelines for treatment of cancer by site n.d. 2017. https://www.nccn.org/professionals/physician_gls/f_ guidelines.asp. (Accessed 4 Jan 2017).

28. Skarsgard LD. Radiobiology with heavy charged particles: a historical review. Phys Medica. 1998;14(Suppl 1):1-19.

29. Particle Therapy Co-Operative Group. Facilities in operation. 2016. https:// www.ptcog.ch/index.php/facilities-in-operation (Accessed 4 Jan 2017).

30. Particle Therapy Co-Operative Group. Facilities under construction. 2016. https://www.ptcog.ch/index.php/facilities-under-construction (Accessed 4 Jan 2017).

31. American Medical Association. AMA code of medical ethics' opinion on physician advertising. Am Med Assoc J Ethics. 2010;12:376-7.

32. AMA Council on Ethical and Judicial Affairs. Code of Medical Ethics. Chicago: American Medical Association; 2016.

33. Olteanu A, Peshterliev S, Liu X, Aberer K. Web credibility: features exploration and credibility prediction. Berlin, Heidelberg: Springer; 2013. p. 557-68. https://doi.org/10.1007/978-3-642-36973-5_47

34. von Elm E, Altman DG, Egger $M$, et al. Strengthening the reporting of observational studies in epidemiology (STROBE) statement: guidelines for reporting observational studies. BMJ. 2007:335:806-8. https://doi.org/10. 1136/bmj.39335.541782.AD

35. Robertson CT. New DTCA guidance - enough to empower consumers? N Engl J Med. 2015;373:1085-7. https://doi.org/10.1056/NEJMp1508548.

36. Boden WE, Diamond GA. DTCA for PTCA — crossing the line in consumer health education? N Engl J Med. 2008;358:2197-200. https://doi.org/10. 1056/NEJMp0801433.

37. Kontos EZ, Viswanath K. Cancer-related direct-to-consumer advertising: a critical review. Nat Rev Cancer. 2011:11:142-50. https://doi.org/10. 1038/nrc2999. 
38. Glatstein E. The return of the snake oil salesmen. Int J Radiat Oncol. 2003;55: 561-2. https://doi.org/10.1016/S0360-3016(02)04204-9.

39. Glatstein E. Intensity-modulated radiation therapy: the inverse, the converse, and the perverse. Semin Radiat Oncol. 2002;12:272-81. https://doi.org/10. 1053/srao.2002.32433.

40. Peeters A, Grutters JPC, Pijls-Johannesma M, et al. How costly is particle therapy? Cost analysis of external beam radiotherapy with carbon-ions, protons and photons. Radiother Oncol. 2010;95:45-53. https://doi.org/10. 1016/j.radonc.2009.12.002.

41. Iversen G. Proton therapy: progress with a price tag. 2014. http://protontherapy.org/dotmed_progress_sept_2014.html (Accessed 17 May 2017).

42. Contreras J, Zhao T, Perkins S, et al. The world's first single-room proton therapy facility: two-year experience. Pract Radiat Oncol. 2017;7:e71-6. https://doi.org/10.1016/j.prro.2016.07.003.

43. Verma V, Mishra MV, Mehta MP. A systematic review of the cost and costeffectiveness studies of proton radiotherapy. Cancer. 2016;122:1483-501. https://doi.org/10.1002/cncr.29882.

44. Verma V, Shah C, J-CM R, et al. Cost-comparativeness of proton versus photon therapy. Chinese Clin Oncol. 2016;5:56. https://doi.org/10.21037/ CCO.V0I0.11097.

45. Rubenson D, Kapp DS. Getting real about NCl-designated cancer center advertising. Nat Rev Clin Oncol. 2017;14:195-6. https://doi.org/10.1038/ nrclinonc.2017.28.

46. Vater LB, Donohue JM, Park SY, et al. Trends in cancer-center spending on advertising in the United States, 2005 to 2014. JAMA Intern Med. 2016;176: 1214-6. https://doi.org/10.1001/jamainternmed.2016.0780.

47. Rosenthal E. Ask your doctor if this ad is right for you. New York times 2016 https://www.nytimes.com/2016/02/28/sunday-review/ask-your-doctor-if-thisad-is-right-for-you.html.

48. Vater $L B$, Donohue $J M$, Arnold $R$, et al. What are cancer centers advertising to the public? Ann Intern Med. 2014;160:813-20. https://doi.org/10.7326/M14-0500.

49. Suit $\mathrm{H}$, Kooy $\mathrm{H}$, Trofimov A, et al. Should positive phase III clinical trial data be required before proton beam therapy is more widely adopted? No. Radiother Oncol. 2008;86:148-53. https://doi.org/10.1016/.j.radonc.2007.12.024.

50. Mitin T, Zietman AL. Promise and pitfalls of heavy-particle therapy. J Clin Oncol. 2014;32:2855-63. https://doi.org/10.1200/JCO.2014.55.1945.

51. Leeman JE, Romesser PB, Zhou Y, et al. Proton therapy for head and neck cancer: expanding the therapeutic window. Lancet Oncol. 2017;18:e254-65. https://doi.org/10.1016/S1470-2045(17)30179-1.

52. Mishra MV, Aggarwal S, Bentzen SM, et al. Establishing evidence-based indications for proton therapy: an overview of current clinical trials. Radiat Oncol Biol. 2017;97:228-35. https://doi.org/10.1016/j.jirobp.2016.10.045.

53. Liao Z, Lee J, Komaki R, et al. OC-0143: a Bayesian randomisation trial of IMRT vs. PSPT for locally advanced non-small cell lung carcinoma. Radiother Oncol. 2017;119:S65. https://doi.org/10.1016/50167-8140(16)31392-5.

54. National Comprehensive Cancer Network. Prostate Cancer NCCN Guidelines (Version 2.2017) 2017. https://www.nccn.org/professionals/physician_gls/ pdf/prostate.pdf (Accessed 24 May 2017).

55. Terashima K, Demizu Y, Hashimoto N, et al. A phase I/II study of gemcitabine-concurrent proton radiotherapy for locally advanced pancreatic cancer without distant metastasis. Radiother Oncol. 2012;103:2531. https://doi.org/10.1016/.j.radonc.2011.12.029.

56. Verma V, Iftekaruddin Z, Badar N, et al. Proton beam radiotherapy as part of comprehensive regional nodal irradiation for locally advanced breast cancer. Radiother Oncol. 2017;123:294-8. https://doi.org/10.1016/..radonc.2017.04.007.

57. Ishikawa H, Hashimoto T, Moriwaki T, et al. Proton beam therapy combined with concurrent chemotherapy for esophageal cancer. Anticancer Res. 2015;35:1757-62.

58. Kagei $\mathrm{K}$, Tokuuye K, Okumura T, et al. Long-term results of proton beam therapy for carcinoma of the uterine cervix. Int J Radiat Oncol Biol Phys. 2003:55:1265-71.

\section{Submit your next manuscript to BioMed Central and we will help you at every step:}

- We accept pre-submission inquiries

- Our selector tool helps you to find the most relevant journal

- We provide round the clock customer support

- Convenient online submission

- Thorough peer review

- Inclusion in PubMed and all major indexing services

- Maximum visibility for your research

Submit your manuscript at www.biomedcentral.com/submit
Biomed Central 